\title{
Todo lo que no cabe en una pantalla
}

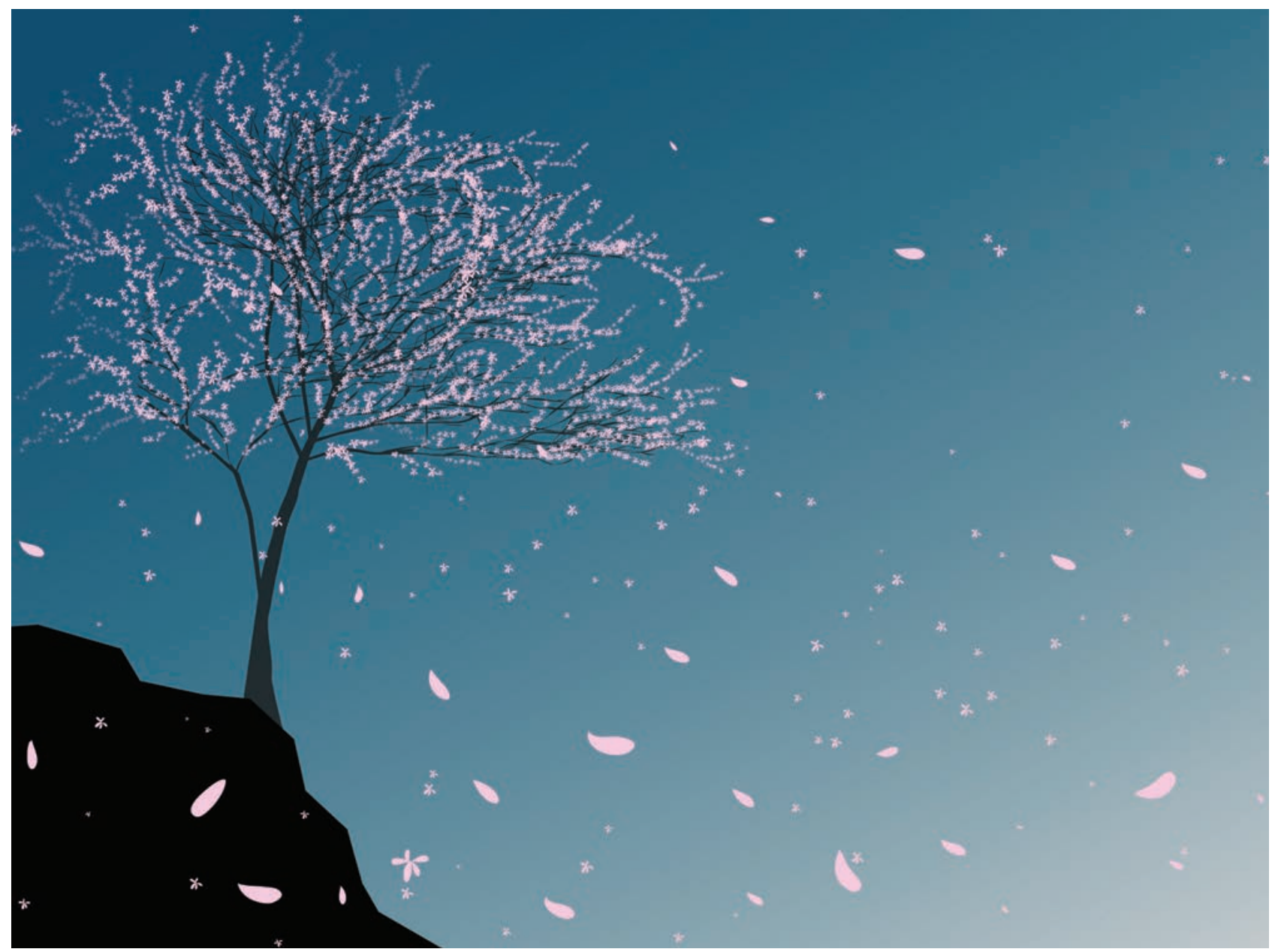

"Where have all the flowers gone...?", cantaba Pete Seeger, y 65 años después las aulas se quedan vacías de un día para otro. Ha cambiado nuestro entorno habitual de interacción y también la colaboración de los alumnos entre ellos. Tenemos equipos docentes que han reaccionado con energía, inteligencia, originalidad e ingenio para aprovechar los recursos $\mathrm{y}$, sobre todo, trabajo en equipo y compromiso. Mucho compromiso. Aquí nos lo cuentan. 


\section{De fiambreras y bolsas del pan}

Recuerdo que nuestros abuelos nos mandaban a la compra con el táper (que antes se llamaba fiambrera), y con una bolsa para el pan... recuerdo a mi abuela tapando las sobras de comida poniendo un plato encima; recuerdo que algunas de sus comidas más maravillosas las hacía con lo que no se comió el día anterior. Recuerdo que nos daban servilletas de tela, y si eran de papel, las partían por la mitad. Recuerdo cómo corrían a cerrar el grifo del agua. Recuerdo a mis padres haciendo lo mismo...

Me vienen, como en borbotones, algunas de las grandes mejoras e innovaciones educativas que he podido conocer y experimentar en los últimos años: el aprendizaje como creación de sentido, la enseñanza para la comprensión, el aprendizaje cooperativo, las inteligencias múltiples... y me he preguntado algunas cosas: si estas innovaciones aportan algo nuevo, ¿qué aportan?; si son tan buenas, ¿nos ayudan a reflexionar sobre la realidad que nos ha tocado vivir estas semanas? Mi respuesta: esta situación las pone a prueba. Más que nunca.

Así que me pregunto si seremos capaces de crear sentido sobre todo esto que está ocurriendo, desde varios puntos de vista: si acepto esta intención desde la óptica de Habermas o de Freire, digo: ¿daremos sentido a esta pérdida de control de nuestras vidas, a esta cura de humildad? iSeremos capaces de crear otro mañana con lo que nos aporta este hoy? Si lo miro desde los ojos de Frankl, me digo: iseremos capaces de encontrar mayor sentido a nuestras vidas desde la resiliencia? ¿Nos da esta situación una oportunidad para mirar más allá en nuestras vidas y preguntarnos qué nos sujeta en ella en los momentos difíciles, cuál queremos que, desde ahí, sea nuestro caminar? ¿Seremos capaces de renunciar a nuestros proyectos para iniciar un nuevo trayecto ( $\sin$ final prejuzgado)? Si me centro en Maturana, me pregunto: ¿queremos vivir el mismo vivir a partir de aquí?, ¿qué queremos conservar?, ¿qué sentido tiene en nuestras vidas y en la de nuestro ecosistema la pérdida de tantos seres humanos?

Siguiendo las reflexiones de Perkins, observo el gran reto planetario de comprender. ¿Qué merece la pena ser comprendido de toda esta tragedia?, ¿de qué nos sirven tantos datos, curvas, picos...? ¿cuál es la verdadera meta de comprensión que nos plantea nuestra antroposfera?, ¿qué merece la pena ser aprendido? Y pienso que, quizá, con una teoría más abierta de la inteligencia, más múltiple (Gardner), encontraremos mejores vehículos de comprensión... Quizá sea la hora de la inteligencia naturalista, del pensamiento circular y visual. Quizá también de inteligencias aún por evidenciar, como la pedagógica y la espiritual; seguro, de las inteligencias emocionales... $Y$ ahora leo mis apuntes de Johnson y Johnson, y los de Kagan... y no puedo evitar volver a Maturana y pensar: todo lo bueno que hicimos como especie fue construido en la colaboración, en el reconocimiento del otro, en el sentir genuino, en el deseo auténtico de compartir y construir desde la igual dignidad de cada ser humano.

Ser inteligente de otra manera, cooperar y comprender son grandes puertas de salida a la creación de sentido, empieza a parecerme bastante claro.

Pienso que muy probablemente pronto saldremos de esto, con crisis económica, social, educativa... pero con nuestra capacidad

\section{Cristóbal Calero Gil}

Fundación Spínola

intacta para destruir nuestro propio ecosistema. Creo, sin ser alarmista ni pesimista, que no tardaremos en recuperar el febril ritmo de destrucción (que solemos endulzar llamándolo crecimiento) de hace solo unas semanas. Creo que a nuestro planeta esto no le importa, no es a él a quien hay que cuidar. Estaba antes que nosotros, seguirá después de nosotros. Creo que nuestro ecosistema, como sistema que es, está sujeto a todas las leyes sistémicas y, por tanto, en su movimiento, seguirá autorregulándose (como principio dinámico, no por voluntad) y creo, por último, que consecuentemente nuestro hacer en la antroposfera está íntimamente ligado con lo que está ocurriendo y con lo que nos ocurrirá en el futuro.

Hoy observo que nos estamos enfrentando a la pandemia con miedo. Un miedo más que natural, pero ¿a dónde queremos que nos lleve ese miedo? Si dejamos que el miedo esté al mando, buscaremos certezas. La certeza es el enemigo de la reflexión... Parece que todos necesitamos saber quién es el malo (como en las películas). Necesitamos constituir a un enemigo contra el que luchar, no en vano todo este periodo ha estado dominado por la dialéctica militar.

En la certeza de encontrar al culpable, aparece una creación de sentido: destruir al enemigo, cerrar filas con el amigo. Es esta lógica, tan presente en las redes sociales y en el discurso político, la que creó las condiciones de nuestro hoy. Eso parece explicar la explosión de rechazo, enfado y fundamentalismos actuales (que son más viejos que nuevos). También parece explicar la incapacidad que sentimos, como sociedad, de encontrar una salida que nos haga sentir bien, a pesar del dolor.

Pero tenemos opciones. También podemos crear otros espacios, en los que no se produzca la negación de quien piensa o siente (0 es) diferente. Podemos poner en el centro otra forma de querer vivir. Podemos intentar comprender con profundidad lo que está ocurriendo, evitar explicaciones simples y culpables, podemos recuperar nuestra esencial capacidad para cooperar. Podemos, y volviendo por última vez a Maturana y Dávila, crear espacios de conversación, donde lo esencial es la disponibilidad de cada uno para cambiar su propia opinión, para co-crear espacios nuevos de reflexión, que no necesitan de certezas para sentirse seguro, pues nadie se siente invisible, pues todos sienten que participan de manera real y honesta de lo que están creando. Tenemos una nueva oportunidad para crear un mañana diferente. No sabemos cuántas más nos quedan.

$Y$ pienso que el táper es la mejor metáfora de nuestros tiempos. Puede que sea la hora de dejar los táperes y volver a las fiambreras. Puede que hava llegado la ocasión de volver a la reflexión y la cocreación amorosa de lo que está por venir, a la falta de certeza que me abre a mí mismo, a los demás y al mundo.

Recuerdo las palabras de Marcelo Spínola como inspiración: "Las palabras convencen, pero los ejemplos arrastran".

Así, afirmo que, para crear sentido sobre lo que nos está ocurriendo, solo podremos hacerlo en el homenaje a todos aquellos que hemos perdido, y aquellos que se han puesto en mayor riesgo: nuestros padres, nuestros abuelos. El homenaje de volver a cargar nuestras alforjas de fiambreras y bolsas para el pan, e iniciar un nuevo trayecto preguntándonos: ¿qué queremos conservar? • 


\section{El coronavirus y los más vulnerables}

Una vez más, los más vulnerables —en esta ocasión las personas mayores y los que menos recursos económicos tienen - han visto sus vidas vapuleadas por una situación ya de por sí difícil para todos. Me gustaría dedicar unas líneas, en concreto, a esos adolescentes que viven cada día de su vida en situación de vulnerabilidad y que ante una pandemia como esta, la ven mucho más agravada.

Tengo la suerte de ser profesora en un colegio que desde sus orígenes optó por educar preferentemente a los más desfavorecidos. Desde que entré a trabajar allí me gustó ese estilo de centro y me sentí atraída por esa tarea. Entré pensando todo lo que tendría yo que enseñarles y aportarles, y cada día que ha ido pasando, al terminar mi trabajo, me he ido a casa con una lección recibida de ellos, de sus vidas, de su realidad, de la dureza a la que algunos se enfrentan cotidianamente con tan solo 12 o 13 años.

Así que cuando llegó esta situación del coronavirus y tuvimos que confinarnos, cada uno en su casa, los primeros días no podía dejar de pensar en esos alumnos: ¿cómo estarán conviviendo tantas personas en pisos muy pequeños, en barrios muy humildes? ¿Habrán hecho un ERTE a sus padres en el trabajo? ¿Tendrán datos/wifi para poder conectarse a internet y hacer las tareas? ¿Tendrán familiares enfermos? ¿Comerán todos los días...?

Detrás de cada una de estas preguntas para mí hay un rostro con nombre y apellido y al que aprecio; por tanto, necesitaba darles respuesta.
Beatriz Núñez Gutiérrez de San Miguel Centro de Formación Padre Piquer

Empezaron las videoconferencias de trabajo entre compañeros y entonces pude apreciar que todos compartíamos esa misma preocupación por muchos de nuestros alumnos y familias. Una vez más me emocionó la grandeza humana de este claustro, cuando en muchos sitios se hablaba de cómo será el final de curso, si volveremos a tener clases presenciales o no, si la EvAU se retrasa, si...; tantos otros interrogantes. Estos profes se preguntaban: "¿cómo están nuestros chicos?". A raíz de ahí, desde la dirección del colegio, con la colaboración del Departamento de Orientación, Pastoral y la ayuda inestimable de los tutores, empezamos a contactar con todas y cada una de las familias y a detectar sus necesidades. Se pusieron en marcha un montón de iniciativas para poder ayudarlos: algunas personales y otras institucionales por parte tanto de la Compañía de Jesús (responsable de la titularidad del centro) como de la Fundación Montemadrid (propietaria del colegio). De este modo, se compraron tarjetas de datos para alumnos, se repartieron lotes de comida a familias, se acompañó "virtualmente" a alumnos con situaciones de soledad 0 ansiedad... que fueron ayudando a paliar poquito a poco el dolor y la necesidad que todos estábamos sufriendo.

$\mathrm{Si}$ algo ha puesto de manifiesto esta pandemia universal es que el ser humano es grande y la solidaridad humana, infinita. Me siento agradecida porque mi trabajo me ofrece oportunidades diarias para intentar ser "grande" y "solidaria" siempre •

\section{¡Lancémonos a abrir las ventanas y vivir!}

El ser humano tiene una gran capacidad de adaptación, signo de ello han sido las últimas semanas, tiempo de mucha incertidumbre, tristeza, dolor, miedo, duelo, nostalgia, soledad, desaliento..., pero también de reflexión, enriquecimiento, ternura, agradecimiento, responsabilidad, aprendizaje y valoración en todos los sentidos.

A las comunidades educativas de los centros, familias, alumnado, profesores, etcétera, se nos enturbiaba la mente por no saber cómo afrontar la nueva situación que se nos presentaba en un estado de alarma, en todos resonaba la palabra "confinamiento", parecía una historia sacada de un libro ciencia ficción. Poco a poco comenzamos a ponernos en marcha, un engranaje extraordinario comenzó a generarse, reuniones, ideas, propuestas, materiales, videoconferencias y un sinfín de recursos para llevar a buen puerto este nuevo barco, siempre con un ambiente colaborativo y capaz de poner en juego la mejor versión de cada uno.

En todo momento hemos hecho una puesta a punto de nuestra astucia, para poder estar cerca del mayor tesoro que tenemos, nuestros alumnos, los hijos, los padres, los hermanos y todas y cada una de las personas que nos rodean y queremos. Ellos han sido y serán el gran motor que nos mueve, nos han motivado para reinventarnos, por ellos nos hemos adaptado, y han despertado la gran solidari-
Aurora M. ${ }^{a}$ Márquez Ruiz

Colegio La Asunción. Montilla (Córdoba)

dad que poseemos. Ahora más que nunca podemos decir que somos capaces de crecer y superarnos, más de lo que nos pensábamos, y tanto los pequeños como los mayores hemos demostrado el valor de la resiliencia.

Ya nada será igual, todo ha cambiado, nos hemos fortalecido y crecido ante la adversidad. Es tiempo de dar un pequeño giro en nuestra vida, de abrir las ventanas de posibilidades, de dejar entrar un aire nuevo que ordene nuestras prioridades, un sol que nos haga brillar como auténticos luceros de bondad y generosidad, una Iluvia que nos empape y deje al descubierto la humildad y la tolerancia, de descubrir un arcoíris de sensaciones, emociones que nos llenen de pasión. Busquemos un nuevo día lleno de serenidad para crecer desde lo auténtico y disfrutemos de los pequeños detalles. Es momento de sanar nuestro corazón. Toca reconstruir nuestra propia historia, ilusionarnos con los regalos que tenemos a nuestro alcance, soñar con un mañana mejor e impulsar un futuro lleno de esperanza donde pongamos en juego el oficio del corazón, AMAR, isí, amar!, al Señor, a uno mismo, al prójimo y a lo que nos rodea.

¡Contagiemos la alegría de tenernos los unos a los otros y agradezcamos el don de la vida! iLancémonos a vivir de una manera diferente donde lo importante sea el cuidado de la vida de todos! • 


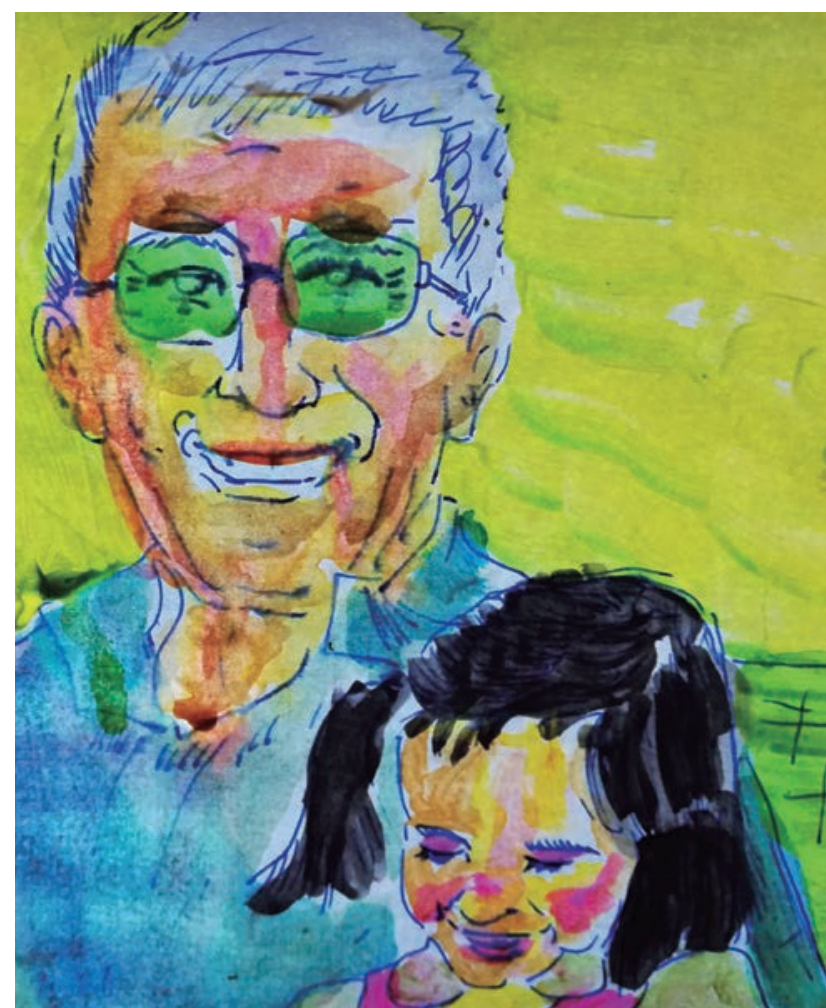

Ilustración de Juan Calvin Palomares

\section{Reflexiones de una maestra en cuarentena ¿cómo vamos a sostener el corazón de nuestros alumnos?}

Mi centro, una vez más, me ha dado una gran lección. El claustro que lo compone ha vuelto a demostrarme que la pasión por lo que se hace, el trabajo bien hecho y el esfuerzo que ello conlleva es generador de cosas maravillosas. Mi labor como jefa de estudios ha sido más que recompensada estos días. Mucho trabajo, sí, pero del que llena: dar seguridad, transmitir confianza, animar, inspirar, coordinar... Al igual que pasaría con mis alumnos, me siento orgullosa de todos y cada uno de los docentes.

Si bien habíamos empezado a caminar en una nueva dirección, esta es una oportunidad para seguir avanzando y cambiar ciertas dinámicas que se encontraban enquistadas. Hemos dado un paso que no habríamos dado en mucho tiempo de no ser por estas circunstancias. Compartir, abrir las aulas, ver que juntos somos capaces de alcanzar más objetivos y sueños que de manera individual, superar miedos e inseguridades son algunos de los regalos y aprendizajes más grandes que nos llevamos estos días, y perdurarán. Estoy segura.

Todas las propuestas para nuestros alumnos Ilevan la impronta característica de cada uno de los maestros que forman la gran familia del Virgen de los Remedios y por esa misma razón, son todas válidas y dignas de considerar. Siguiendo unas líneas comunes, hemos creado algo nuevo y diferente. ¿Lo ideal? No lo sé. Nadie lo sabe. Lo que tengo claro es que el aprendizaje de nuestros alumnos está cubierto y cuidado con mucho cariño desde el corazón de los docentes. Sin embargo, falta algo muy importante, algo que sostiene todo lo demás, el apoyo emocional que tanto necesitan día a día.

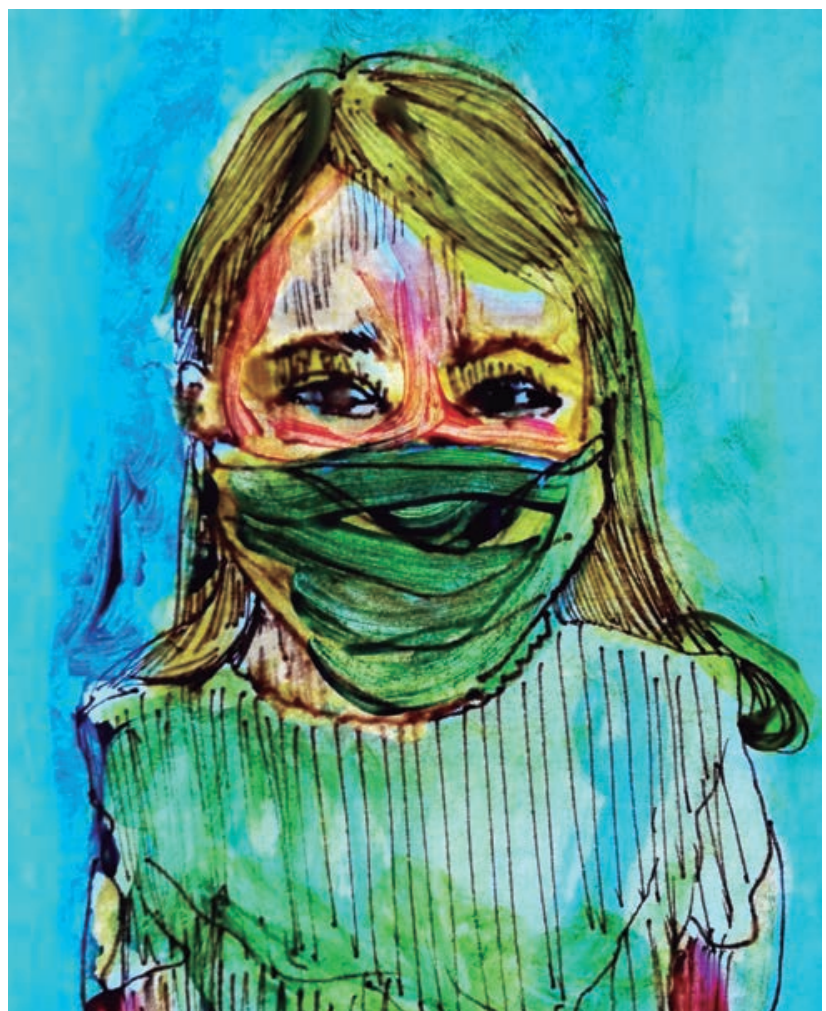

Ilustración de Juan Calvin Palomares

Esther Vaquero García de Yébenes Colegio Público Virgen de los Remedios

Ese, ¿cómo se está protegiendo?, ¿cómo hacer llegar a nuestros alumnos un abrazo, una sonrisa de forma virtual? ¿Acaso tienen la misma fuerza que los de verdad?

Margaret Shafer afirma que "las relaciones con sus alumnos forman parte de su enseñanza, y que las relaciones que se establecen entre los propios estudiantes son vitales para disfrutar del colegio y del aprendizaje" (Gonser, 2020, 7 Ways to Maintain Relationships During Your School Closure). Por eso es tan importante que les hagamos saber que estamos ahí para ellos y que nos acordamos, les echamos de menos, generando asimismo oportunidades de interacción e intercambio entre los propios alumnos.

A pesar de las circunstancias, mantengo la esperanza. Nuestros niños están viviendo una experiencia que va a cambiar la perspectiva de su vida. Esa generación que considerábamos perdida y ensimismada con tanta pantalla e irrealidad se ve de repente confinada y necesitando de una paciencia como jamás antes se les había pedido.

Cada alumno irá avanzando en la medida de sus posibilidades y eso no nos tiene que preocupar ni llevar a una angustia sin sentido. Citando a mi gran amigo y maestro Jorge Burgueño, "Ios ritmos de aprendizaje en un aula son diversos, y muchas veces no tenemos la paciencia suficiente para apreciar los avances de aquellos a los que les cuesta más. No dejemos de ser el viento imparable que empuje y dé forma a nuestros alumnos. Si no hay viento, las nubes no se moverán" (2020, Las formas de las nubes).

Recordemos eso y seamos la cálida brisa que siempre los acompañe, aun en la distancia • 


\section{El confinamiento en la ESO: flexibilidad, crecimiento y reto}

8:30h.

- ¡Rápido! A lo largo de la mañana debe quedar elaborado un documento con todas las tareas que los alumnos deberán realizar en estos próximos 15 días, proporcionales al número de horas lectivas correspondientes. Elaboradlo con vuestros compañeros de nivel. Lo entregaremos en papel y además lo enviaremos digitalmente a alumnos y familias.

12:00h.

- Buenos días. Perdonad que interrumpa la clase.Vengo a advertir a todos que los próximos días de confinamiento y cierre del centro no son de vacaciones, sino que continuará el desarrollo de la actividad académica, al igual que las evaluaciones previstas...

14:00h.

Recogida exhaustiva de todos los materiales. Aleccionamiento de alumnos y profesores.

Con rigor, pero sin agobio, el 10 de marzo de 2020 se puso en marcha un engranaje telemático que aún un mes después nos sigue sorprendiendo.

Ingredientes: bagaje digital ("dónde quedaron algunos antiguos resquemores...", "ipara qué hace falta un dispositivo digital por alumno?", "iCuánto curso de informática!”...); bagaje organizativo y fluidez en la comunicación (desde el día 11 de marzo seguíamos manteniendo nuestras reuniones por videollamada); alumnos que se saben adaptar gracias a la flexibilidad largamente exigida por las aulas cooperativas multitarea, clima de centro esforzado y positivo, y tutores que andan no con 100 ojos, sino con 900: uno por alumno 0 alumna y por cada día del mes.

A continuación comenzó una carrera de puesta a punto y desarrollo de todo lo previsto inicialmente. ¿Es preferible impartir clases por Hangouts o con Teams? ¿Zoom es también seguro? ¿Se puede compartir pantalla desde el iPad o solo desde el ordenador? ¿Hay algún alumno de mi tutoría que no os esté
Inmaculada Medrano Samper

Centro de Formación Padre Piquer

mandando las tareas? ¿Y Juana, que se ha ido al pueblo con sus padres y no tiene internet? ¿Cómo pautamos, recogemos y calificamos cada una de las tareas? ¿Cómo motivar el aprendizaje? (Vivan los Quizziz, que desarrollamos a buena velocidad, los Edpuzzles, y otras mil aplicaciones) ¿Y la atención a la diversidad? Reprogramemos, registrémoslo todo, mejoremos la competencia digital... Todo ello ha supuesto, en fin, un gran esfuerzo en todos los órdenes, tal vez un poco mayor aún para los docentes de más edad.

$Y$ desde el Departamento de Pastoral nos hemos planteado qué hacer con el desarrollo de la interioridad. Hemos mantenido nuestros grupos por videollamada. Estamos realizando un acompañamiento desde lo espiritual a los alumnos con familiares fallecidos; hemos abierto Padlets (una especie de muros donde los chavales están colgando sus vivencias y mensajes de ánimo, oraciones, etc.), hemos enviado materiales de Semana Santa a las familias... La imaginación solo tiene los límites de una disponibilidad horaria que, inevitablemente, se ha visto ampliada. Sorprende ver cómo los chavales también se han organizado rápidamente entre ellos: han formado grupos virtuales de trabajo, descubren nuevas aplicaciones para ayudarse en los estudios... Los profes hemos llegado con ganas a las vacaciones de Semana Santa; con ganas físicas, psicológicas y espirituales porque sabemos que aún nos quedan muchos retos por delante: que no se quede atrás ni un solo alumno, por más dificultades personales 0 técnicas que encuentre, minimizando en todo lo posible la brecha cultural y digital; que no dejemos de seguir aprendiendo; que el contacto y la atención individualizada (en la que, sin duda, hemos ganado) continúen incansablemente dando sus frutos, y que se siga produciendo esa característica tan propia de Padre Piquer: la cercanía entre los miembros de su Comunidad Educativa, que ni este virus ha podido mermar •

\section{Tenemos que estar preparados}

Nunca se puede estar lo suficientemente preparado. Cuando preparas una clase hay multitud de elementos que tienes que tener en cuenta: la explicación de las tareas, el material que vas a utilizar, las adaptaciones para alumnos específicos, hacer la clase entretenida y útil al mismo tiempo... Este es mi primer año como maestro y lo primero que he aprendido es que, aunque creas tener todo bajo control, siempre hay algo que se te escapa. Estos inconvenientes surgen sin previo aviso y tienes que estar dispuesto a hacerles frente. Sin embargo, hay cosas para las que es difícil estar preparado. Que cierren los colegios por culpa de un virus que viene de lejos es una de esas cosas.

Está claro que hay cosas para las que es casi imposible estar preparado. A nadie se le ocurrió programar un trimestre entero basado en actividades online, videos grabados en casa y tutorías por
Nicolás Vaquero García de Yébenes

Maestro de Educación Primaria

videollamada. Era impensable que algo así fuera útil y necesario, pero ha sido la única forma de llevar a cabo nuestra labor. Hemos tenido que adaptarnos de forma rápida y algo brusca, pero creo poder decir que estamos llevando todo a buen término.

En mi caso, tuvimos que crear un blog en el que hemos ido recogiendo las tareas semanales, así como distintas actividades y videos explicativos. He de reconocer que antes de todo esto mis nociones de edición de video y de creación de formularios y actividades online eran bastante limitadas. He tenido que ir ampliándolas poco a poco hasta el punto en un que más o menos me defiendo y puedo crear material útil para los alumnos.

Adaptarse a esta nueva realidad no ha sido fácil. Los espacios de relajación y distensión, nuestros hogares, se han convertido en 
nuestros puestos de trabajo. Seguir ciertos horarios ayuda a no perder la dirección y a separar el tiempo de trabajo y el tiempo que necesitamos para nosotros mismos. Aun así, el encierro ha tenido graves efectos sobre la moral de muchos. Muchas otras cosas nos siguen preocupando y no debemos ignorarlas y pretender que no están ocurriendo, pero tampoco debemos permitir que nos impidan seguir adelante.

Todo el trabajo que estamos llevando a cabo puede ver limitada su efectividad debido a numerosas circunstancias como una mala conexión a internet o la falta de medios tecnológicos. Sin embargo, el factor más importante en primaria ha sido la ayuda de los padres, que es indispensable. Son principalmente ellos los que se encargan de ver el blog, subir archivos y, naturalmente, de asistir a sus hijos en la realización de las tareas. Dependemos de ellos para mantener el contacto y poder seguir ayudando a los alumnos, sobre todo con los más pequeños. Por suerte, en mi caso, he conseguido mantener el contacto con casi todos los alumnos de mi tutoría en $3 .^{\circ}$ de primaria y esto es algo que agradezco enormemente.

En cierto sentido esta crisis ha ayudado a cambiar algunas de las ideas que ciertas personas tenían acerca de la labor de los maestros en los centros. Los padres han podido ver de primera mano la gran cantidad de trabajo que se desarrolla día a día. Nuestra función va más allá de ponerse al frente de una clase y soltar una interminable perorata. Desde la distancia podemos organizar y proponer, pero es de los padres de quienes depende la ejecución y la realización de las actividades. Muchos han comprobado que no es sencillo trabajar con niños, ni siquiera siendo tus propios hijos. Espero que esto ayude a percibir de otra manera nuestra profesión y permita empezar a mejorar la desastrosa imagen que tiene la educación en este país.

El mundo va a seguir cambiando, ya sea por eventos extraordinarios como el que nos ha tocado vivir o por la simple evolución de la sociedad y la tecnología. Elementos como las tecnologías de la comunicación e incluso la impresión 3D están resultando esenciales para la resolución de esta crisis. Como maestros, creo que es de vital importancia identificar estos elementos clave y formarnos para poder enseñar a nuestros alumnos. No podemos ser analfabetos digitales en el mundo del mañana y los niños necesitan maestros que les enseñen a dominar ese aspecto de la realidad. Ser un nativo digital no será suficiente en el mundo que viene. Nunca es demasiado pronto para empezar a sentar las bases de lo que puede ser una parte esencial de nuestro futuro. Tenemos que estar preparados •

\section{Mi experiencia en la época del coronavirus}

Madrid es una ciudad de más de cinco mil cadáveres ("según las últimas estadísticas"). Y a veces, en la noche, yo me revuelvo y como Dámaso Alonso también paso largas horas "oyendo gemir al huracán". Los muertos han dejado de ser una estadística para ser rostros cercanos de amigos, de familiares, de personas allegadas a nuestros alumnos y a nuestro colegio. Y ya no son un número, son una muesca de dolor en el corazón. En este contexto encuadro lo que os voy a relatar. Me han pedido que escriba mi experiencia como profesora en estos días tan duros del coronavirus y que me centre en la etapa de Bachillerato.

Ser profesora estos días ha supuesto para mí un reto. También un deber moral y la confirmación de que esta es una de las profesiones más bonitas del mundo.

Un reto. En la etapa de Bachillerato, en Padre Piquer Ilevábamos dos años trabajando con dispositivos digitales. Esta iniciativa pedagógica, que tuvo su proceso de reflexión en el claustro, ha resultado ser una bendición y nuestra salvación. Ese día 10 de marzo en el que tuvimos que recoger todos nuestros materiales porque la Consejería de Educación había declarado el cierre de los colegios, teníamos asegurado que en cada casa de cada alumno había un dispositivo que contenía a su vez los libros digitales, las aplicaciones y el acceso a todos los materiales del curso y la comunicación con los profesores. El resto fue relativamente sencillo: aprender a dar clase a través de tutoriales, mandar y corregir las tareas vía Classroom, comunicarnos con los alumnos por videoconferencias, descubrir nuevas aplicaciones que mantuvieran la motivación de
Marta Gómez Recasens

Centro de Formación Padre Piquer

los chicos y chicas, intercambiar esfuerzos e iniciativas con otros compañeros profesores. Los alumnos han sentido en todo momento que seguíamos ahí detrás de sus pantallas y que nos las estábamos ingeniando para darles clase de otra forma. Hemos aprendido mucho de tecnología en estos días y de trabajo en equipo, sin duda.

Un deber moral. Los sanitarios y los vendedores de supermercados han estado a la altura sin duda en estos días duros. No les quedaba otra. El deber de los profesores ha sido mantener la rutina académica de los alumnos. Tampoco nos quedaba otra. No habíamos elegido dar clase así pero era nuestro deber estar a la altura de nuestros alumnos. La etapa de bachillerato es una etapa muy intensa, pues abarca solo dos cursos escolares y supone abordar todos los contenidos y terminar los temarios. La gran mayoría de los alumnos cursa Bachillerato para acceder a un grado universitario 0 a un ciclo formativo. Y hay que prepararlos para ello. Les suele preocupar mucho la nota media con la que terminan, porque esa nota condicionará su acceso a estudios posteriores. Es una etapa académica preciosa porque los alumnos deciden su futuro y es muy bonito acompañarlos en esa decisión, en ese sueño y dotarlos de recursos para que lo consigan. Por esta razón ser profesor en la época del coronavirus ha sido también un deber moral.

Por último, hemos entroncado con la esencia más profunda de nuestra vocación. Con el cierre de los colegios llegaron el confinamiento, el parón de nuestras rutinas habituales y las preguntas. ¿Por qué he querido ser yo profesora? He querido serlo no solo para estar en el aula con un grupo de adolescentes a los que transmitir 
unos contenidos. No. Ser profesor jamás ha sido solo eso. Ser profesor es apreciar a los alumnos sean como sean, es desear educarlos, transmitirles valores, tratar de ser un referente para ellos, apoyarIos, ayudarlos a crecer, estar a su servicio y disposición.

Ante la crueldad de las estadísticas del primer párrafo estoy segura de que cada profesor de este país se ha levantado cada mañana con la convicción de que tenía que tirar de la vida y de las ilusiones de sus alumnos. Les hemos dado clase con tutoriales para que siguieran escuchando nuestra voz, para recordarles que esta epidemia no iba a terminar con nuestros sueños y planes de futuro, los hemos Ilamado por teléfono si no se conectaban a las videocon- ferencias, hemos intentado por todos los medios que ningún alumno se quedara atrás, los hemos felicitado cada vez que recibíamos sus tareas, les hemos recordado que saldría el sol después de esta epidemia y que ese rayo de sol nos tenía que pillar con la conciencia de que nuestro tesón era más fuerte que el virus. Recuerdo que el primer día de curso los tutores les dijimos a nuestros alumnos que el tutor en Padre Piquer es "aquel que te da la mano y no te la suelta". El gran equipo humano de profesores y tutores de Piquer no ha soltado la mano de ningún alumno en estos meses tan difíciles. Y creo que esto nos ha unido más a nuestros alumnos, a nuestras familias, pero también al sentido más profundo de nuestra vocación •

\section{Coronavirus y FP}

Como director de una etapa algo "olvidada" en todas las reflexiones que surgen acerca de cómo hacer frente a esta desgracia llamada Pandemia, y más aún, al hacerlo desde un centro educativo que lleva más de 15 años volcado en la innovación educativa y más de 50 años de experiencia en formar profesionales, puedo asegurar que, por suerte, no nos está yendo nada mal.

Nuestro sistema de trabajo basado en ordenadores convertibles y temarios digitales nos está ayudando desde el primer día a poder mantener un ritmo y desarrollo de la gran mayoría de los módulos profesionales. Además, al contar con herramientas de uso activo en nuestra comunidad mucho antes de la crisis como Classroom, Moodle, Teams, Gsuite, etc., se está haciendo un seguimiento personalizado de cada alumno, correcciones online, videoclases, tutoriales...

Evidentemente, el caso particular de la Formación Profesional implica que no solamente impartimos conocimientos, sino también competencias profesionales de carácter netamente técnico y que precisan, no ya de un abordaje presencial, sino, sobre todo, de infraestructuras y materiales difíciles de sustituir en la modalidad online. ¿Cómo enseñamos a soldar en electrónica? ¿Cómo podemos enseñar a usar una grúa para mover enfermos? ¿Cómo a instalar una placa base en informática? Es verdad que existen videotutoriales, mucha información en la red, etc. Pero para poder decir que eres bombero, hay que haber estado frente al fuego y no verse infinitas veces El coloso en llamas en YouTube.

De ahí que nos preocupe en primera instancia —y no sepamos qué ocurrirá ni cómo se resolverá con estos alumnos - la "recuperación" de ese tipo de competencias, tanto más en los alumnos que deberían graduarse en grado medio y en grado superior sin haber podido desarrollar siquiera sus periodos de prácticas en empresa.

A este respecto, entendemos que es un momento excepcional y que, por lo tanto, requiere medidas excepcionales, pero tenemos que asegurar las competencias profesionales mínimas, puesto que no deberíamos sacar al mercado laboral profesionales acreditados con
Roberto Alonso Valdesueiro Centro de Formación Padre Piquer

un depósito vacío o a medias, más sabiendo que muchas de estas competencias mal adquiridas pueden poner en riesgo la propia seguridad pública: atención sociosanitaria, instalaciones electrónicas, instalaciones de gas...

La auténtica solución a todas las cuestiones educativas va a seguir pasando por el margen de maniobra individual de cada centro, y a este respecto, me consta que no solo Padre Piquer, sino que son muchos centros de FP los que se están reinventando para poder asegurar estos procesos de enseñanza.

La suerte en nuestro centro es que formamos una gran comunidad docente entregada a la excelencia en su trabajo, acostumbrada a trabajar con la innovación bajo el brazo y a los cambios de escenario. Por eso hemos sido referentes en muchos casos y pondremos nuestro propio granito de arena para compartir y hallar soluciones eficientes para nuestros alumnos, que son nuestra absoluta prioridad.

Este afán de llegar a más permite acciones solidarias como que, gracias a la posibilidad de contar con algunos materiales como las impresoras 3D, se ha podido y se sigue participando activamente en la dotación de viseras de protección a residencias de ancianos, farmacias, policía, guardias civiles, empleados de supermercados, etc. Cada docente, cada centro, cada etapa deberá remangarse desde YA y ponerse "neuronas a la obra" para diseñar su propio "plan de rescate".

Especial consideración tiene nuestro alumnado de la etapa de Formación Profesional Básica. Un salvavidas para muchos de ellos que ahora más que nunca tenemos que mantener a flote. De ahí que el acompañamiento profesional debe ser una de las bases de nuestras acciones en estos momentos, sin olvidar el acompañamiento personal de estos alumnos y sus familias, donde en muchos casos ya de manera natural es necesario.

Somos un centro dirigido por la Compañía de Jesús y sabemos que "en tiempo de desolación, no hacer mudanza", pero sí debemos abrir procesos de discernimiento que nos lleven a dar soluciones, siempre con nuestros alumnos en el centro de nuestro colegio • 


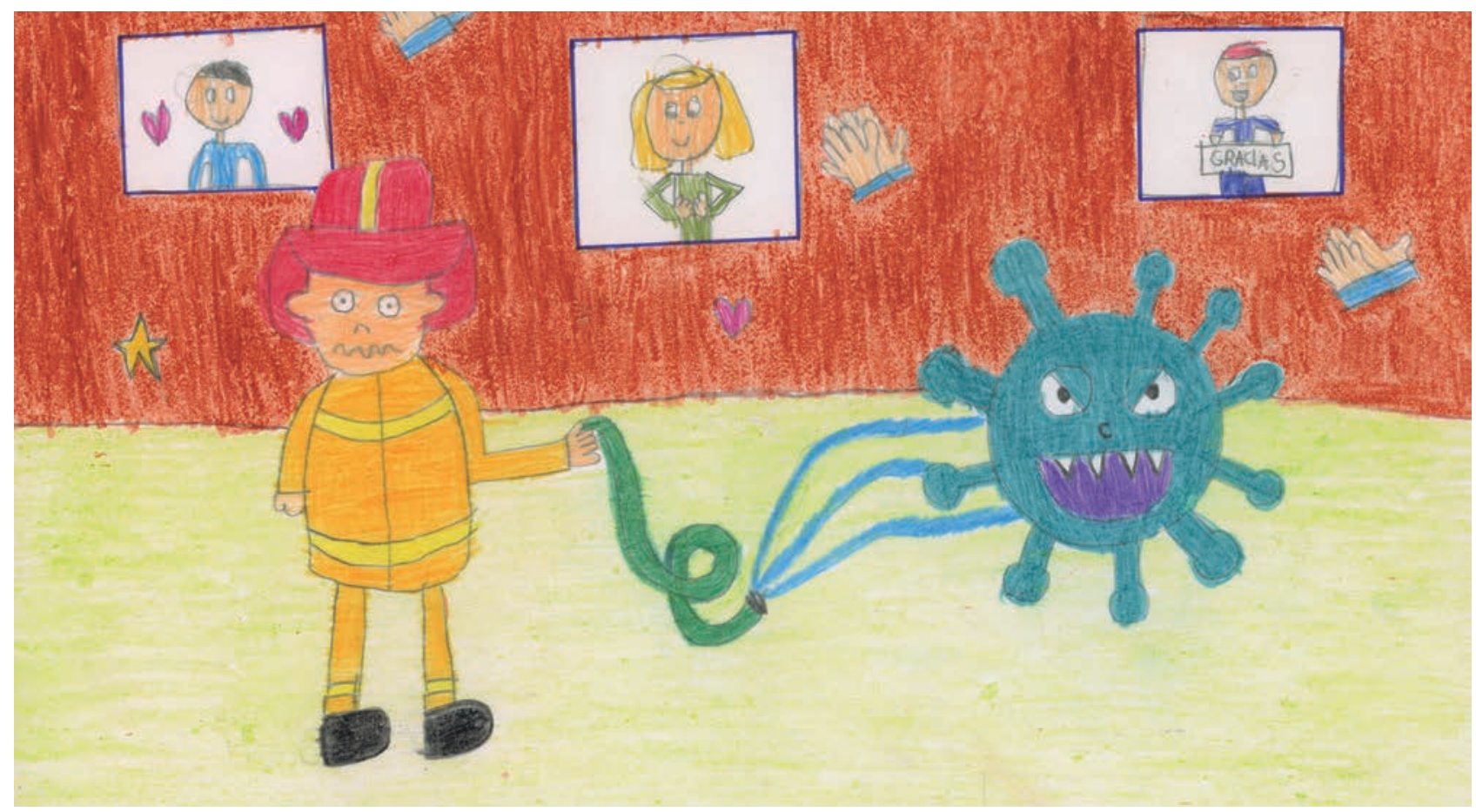

Ignacio (3. ${ }^{\circ}$ Primaria)

\section{"El coronavirus tiene muchos brazos, una cara redonda y vuela". Segundo ciclo de Educación Infantil}

La situación que el coronavirus ha provocado en nuestra sociedad es algo que muchos de nosotros no podíamos ni imaginar cuando se empezó a hablar del tema. Hemos podido experimentar en pocos días cómo nuestras vidas han dado un giro de tal magnitud que nos ha obligado a vivir lo cotidiano de forma totalmente diferente. Nuestras casas se han convertido en protagonistas absolutas. Son ahora el espacio de trabajo, ocio y relación de una forma exclusiva.

Estamos aprendiendo la riqueza de la comunicación y la convivencia entre los miembros más íntimos de la familia, que más que nunca ahora lo comparten todo. Y dentro del horror de la situación sanitaria y social que estamos viviendo, la convivencia y la comunicación familiar en auge es una buena noticia.

Los padres se esfuerzan por estar con los hijos de una manera especial para ofrecerles los estímulos, las diversiones y los conocimientos que el confinamiento les hurta a los más pequeños. Pero, sobre todo, los padres les ofrecen a los niños tiempo. Tiempo de calidad, un bien del que muchos de nuestros pequeños seguro que no disfrutaban, y que muchos padres echaban de menos en sus vidas e intentaban compensar con premios.

Ahora, cada casa ha tenido que cambiar las normas y crear nuevos espacios. Reinventarse para estar, y estar bien con los niños, caminar juntos y preparar a los pequeños para la larga vuelta a la normalidad que nos espera a todos.

Los niños de 3 a 6 años entienden mucho mejor las cosas de lo que muchas veces pensamos los adultos. Evidentemente les falta la capacidad para expresar y responder con nuestra lógica a determinadas preguntas y situaciones, pero esto no implica que no conozcan e interpreten el entorno en el que van creciendo.
Estas destrezas de los más pequeños se ven reforzadas gracias a las nuevas tendencias educativas en las que se están formando los alumnos de Educación Infantil. La escuela actual potencia que los niños piensen, reflexionen, compartan ideas, las comuniquen y busquen diferentes respuestas creativas a las cuestiones que se les plantean.

Con frecuencia las respuestas de los niños frente a diferentes realidades nos sorprenden por su lógica, por su sencillez y claridad, y por la cantidad de conocimientos que han ido reteniendo y elaborando. Me he permitido preguntar a algunos niños de entre 3 y 6 años sobre la situación del coronavirus, para escuchar la frescura de sus respuestas que resultan muy ilustrativas. Les he realizado las siguientes preguntas, y os muestro algunas de sus respuestas:

\section{1. ¿Por qué no podemos salir a la calle?}

Niño 3 años: Porque es de noche, no se puede salir, es la hora de dormir. No podemos salir porque está el virus en la calle, es sucio y mancha las manitas, hay que lavarse las manitas, el virus está andando.

Niño 3 años: Porque está el virus, son pequeñísimos del todo, de tan pequeñísimos que son ni se ven y son amarillos.

Niña 3 años: Porque hay un virus en la calle, en la acera, no nos deja salir la policía.

Niña 3 años: Por el coronavirus, que es algo que vuela.

Niña 4 años: No podemos salir porque hay virus y nos pueden hacer daño. Los virus son como un palito, como los del cuerpo humano de la serie que vemos, 0 también pueden ser circulitos. Se Ilama coronavirus. 
Niña 4 años: El coronavirus no nos deja salir de casa es malo, malo, muy malo, hace que haya distintas enfermedades malas y para protegernos de esas enfermedades nos protegemos en casita y ya está. Y estamos enfadados y tristes porque queremos que se vaya. Ves, aquí he dibujado a las personas libres porque ya se ha ido y aquí estoy yo muy contenta porque ya no está.

Niño 4 años: Porque está el virus, el coronavirus. El coronavirus tiene muchos brazos y una cara redonda y vuela.

Niño 5 años: Por el coronavirus, para no infectarnos, para que no cojamos el coronavirus, y si estás malito vas al médico.

Niña 5 años: Porque está el coronavirus, ha venido, es un bichito, un microbio que le gusta viajar mucho y ha venido a la tierra para que toda la gente se ponga malita.

Niño 6 años: Porque hay coronavirus y nos ponemos enfermos.

\section{2. ¿Crees que hay algunas personas que sí están saliendo a la calle? ¿Quiénes son esas personas y por qué salen?}

Niña 3 años: La policía, que dice "No puedes salir porque soy un señor". Y damos palmas a Elena, a Paula y a Roberto porque son médicos.

Niña 3 años: Sí, un señor para ir a su casa, yo lo vi, había tres y le dije que no.

Niña 4 años: No, ninguna..., a lo mejor si es una cosa muy importante..., 0 a lo mejor una policía que está vigilando a todos para que no salgan. Una cosa muy importante es salir a comprar, porque no podemos matar a los bichos si no tenemos energía.

Niño 4 años: Sí, para jugar, para buscar cosas y serpientes. Yo no puedo salir por el coronavirus y los que salen se convierten en virus.

Niño 5 años: Nadie sale a la calle, pero algunos trabajan en el supermercado.

Niña 5 años: Sí, los enfermeros con los coches salen porque hay algunas emergencias, que algunos abuelitos se están poniendo malitos y por eso tienen que ir al hospital.

Niño 6 años: Sí, algunos, porque solo puede salir uno de casa, el que elijan, para comprar cosas.

\section{Si pudieses salir a la calle ahora, ¿a dónde te gustaría ir?}

Niño 3 años: Cuando se vaya el virus quiero ir al museo.

Niño 3 años: A una noria.

Niña 3 años: A ver a un DJ.

Niña 3 años: A Dino Pepino y, si está abierto, entramos a la piscina de pelotas.

Niña 4 años: Al parque de atracciones, me quiero montar en cosas peligrosas, en cosas de mamás y papás y de abuelas y de abuelos.

Niña 4 años: Saldremos a comprar algo por si viene otro virus.

Niño 4 años: Con amigos míos al parque acuático y al castillo encantado de Frankenstein.

Niño 5 años: Al parque de atracciones 0 al parque acuático.
Niña 5 años: Ir con cuidadito porque hay personas que están malitas y si los tocamos pues nosotros nos infectamos de ellos.

Niño 6 años: Al pueblo para jugar un partido con mis primos, porque es muy chuli.

Todos estos niños saben...

$\checkmark$ Que el coronavirus es el motivo por el que no podemos salir de casa.

\ Saben además que es pequeño y que llega a todas partes.

У Saben también que no pueden salir a la calle, pero sí perciben que hay excepciones y cada uno lo reconoce a partir de sus experiencias.

У Y para cuando termine la cuarentena, lo que quieren es revivir una experiencia gratificante.

$\searrow$ Aunque dos de nuestras protagonistas piensan que seguirá siendo una situación diferente y nos piden prudencia y previsión.

Como no puede ser de otra manera, esta miniencuesta solo pretende ilustrar algunos de los planteamientos que vamos a exponer.

Los niños viven en presente, si el presente cambia de forma radical necesitan respuestas claras y verdaderas para entenderlo. Es muy conveniente hablar expresamente de este tema con nuestros hijos.

Es muy esclarecedora la respuesta que dice: "No se puede salir porque es de noche, es la hora de dormir". Una aplastante respuesta que da la certeza del ahora mismo. Una forma de acompañar en el crecimiento a los niños es presentarles la realidad desde la verdad, la claridad, y a ser posible ejemplificando, ayudándoles a entender lo que está pasando.

La misión del adulto es compartir con los niños lo que sentimos, sabemos y pensamos, adaptándolo a su lenguaje y su sensibilidad para ayudarlos a ordenar sus ideas y emociones. En la comunicación hay que evitar la crudeza, pero no edulcorar de tal forma que se evapore la realidad y perciban mensajes cruzados entre lo que dicen los adultos con los que convivo y lo que percibo en el ambiente.

Para llegar a una comunicación real con el pequeño es mejor hacerlo desde el diálogo, animándole a dar sus respuestas y completándolas 0 encauzándolas si es necesario. Verbalizar, poner en palabras los hechos y las emociones es la clave para construir el pensamiento y comprender las experiencias que vamos viviendo.

Solo cuando el niño se hava expresado con libertad y se hayan ido compartiendo y aclarando todas las facetas de la cuestión, el adulto podrá hacer un resumen, utilizando preferentemente los argumentos y las expresiones del niño, para que el pequeño sepa que ha sido escuchado y que sus aportaciones han sido valiosas.

\footnotetext{
“Ahora nos está pasando esto..., por esto... y para ayudarnos entre todos lo mejor que podemos hacer es ..."
}

Los niños, como todos, necesitan vivir su vida de cada día, con la mayor normalidad posible, generando nuevas rutinas. 


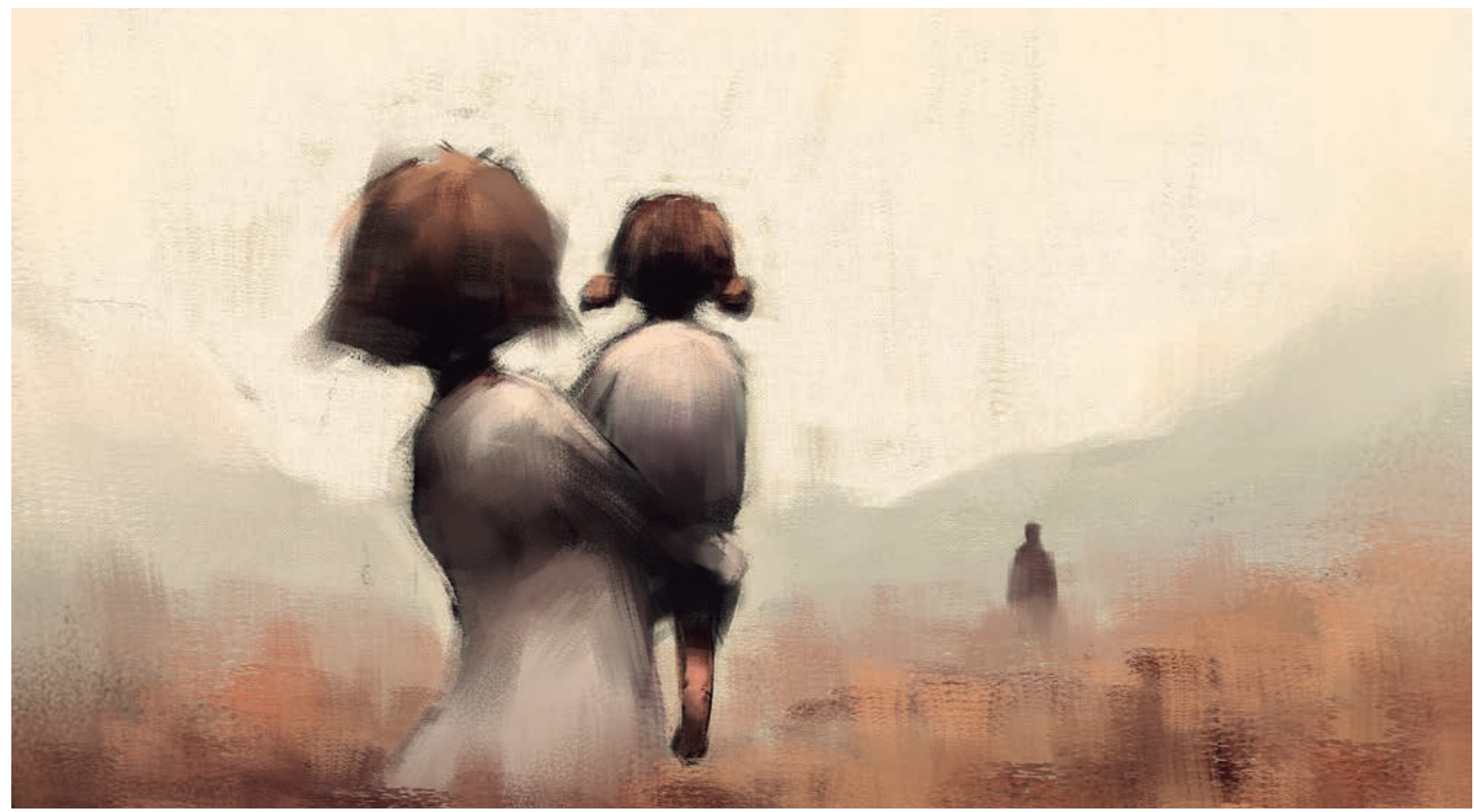

Durante las semanas del confinamiento, los que hemos estado en contacto con niños pequeños hemos podido comprobar que son capaces de adaptarse, de afrontar cambios de costumbres, sobre todo si se les explican los porqués y se les da la oportunidad de un cierto protagonismo haciéndoles corresponsables de los nuevos hábitos y necesidades.

Los niños menores de 6 años no hacen muchos planteamientos de futuro, más allá de lo que les van anticipando los adultos, por ello es muy importante orientar de forma positiva sus expectativas.

La misión de los padres es ir preparando a los niños de forma progresiva, para esa vuelta a la normalidad. Un proceso que será cambiante, unos meses de costumbres y hábitos diferentes en los que todos vamos a tener que vivir y a los que nos vamos a tener que adaptar. Si en esta nueva y extraña etapa de nuestra existencia somos capaces de introducirnos en un diálogo permanente con los niños, todo va a ser mucho más fácil y beneficioso. En la comunicación con los niños tenemos que estar muy abiertos para escucharlos, entenderlos y descubrir el momento emocional por el que están pasando. Solo así podremos responder a sus dudas y minimizar sus temores.

De nuevo tenemos que estar completamente aliados. Ellos tienen que desempeñar un papel importante, animándose y animándonos a seguir las normas y recordándonos las medidas que tengamos que tomar, conociendo lo que adultos y menores tenemos que hacer en las nuevas circunstancias, para que cada uno asuma la parte de protagonismo que pueda asumir.

Cómo deben ir por la calle, qué podemos y no podemos hacer y por qué..., son dudas que los niños deben resolver con sus padres. Todo ello dentro de un clima de tranquilidad y seguridad. Los niños deben tener la certeza de que si todos nos ayudamos a cumplir las normas todo irá bien y estaremos trabajando juntos para hacer algo bueno para todos, seremos solidarios.
Los niños del segundo ciclo de infantil, a pesar de su fuerte egocentrismo, disfrutan mucho cuando preparan una sorpresa para alguien. Esto les afianza su ego, pues ya son capaces de dar, de hacer y de pensar en algo para el otro. En definitiva, sentirse implicados. Cuando estamos pensando en el bien de los demás y somos generosos estamos dando, sin duda, un paso importante hacia la madurez. Por ello ser protagonistas de este proceso les puede hacer sentirse útiles y felices.

En estas reflexiones hemos hablado de la comunicación con los niños, de escucharlos, de oír sus propuestas y sugerencias..., pero no todos los niños tienen esa disposición, ni esa capacidad de comunicación verbal para comunicarse en profundidad, para vaciarse y compartir sus emociones.

Por ello os invitamos a que uséis las estrategias que se han usado siempre desde la escuela:

Utilizad el juego simbólico, con los juguetes y personajes preferidos de vuestros hijos, aquellos de apego con los que se identifican. Usad, si los tienen, a sus amigos imaginarios, a ellos con frecuencia les cuesta menos hablar que a sus dueños.

Y no os olvidéis del dibujo. Que dibujen lo que están viviendo y os expliquen cada detalle de lo que hayan sido capaces de plasmar en el papel. Por complicado y confuso que parezca.

Contad cuentos, inventados o no. Han aparecido muchos en las redes que hacen referencia a lo que estamos viviendo, para después comentarlos con ellos, o usarlos de forma combinada con el dibujo y el juego simbólico.

Antes de que todo esto empezase teníamos muchas cosas importantes, proyectos que en algunos casos están parados, 0 que se han quedado atrás para dejar paso a otros nuevos o que nos agobian por la urgencia y el cambio de escenario. Todos nos hemos tenido que recolocar, los niños también, por eso ellos nos necesitan más que nunca. Vive con esperanza y transmíteles ese amor que solo un padre 0 una madre pueden dar a sus hijos • 


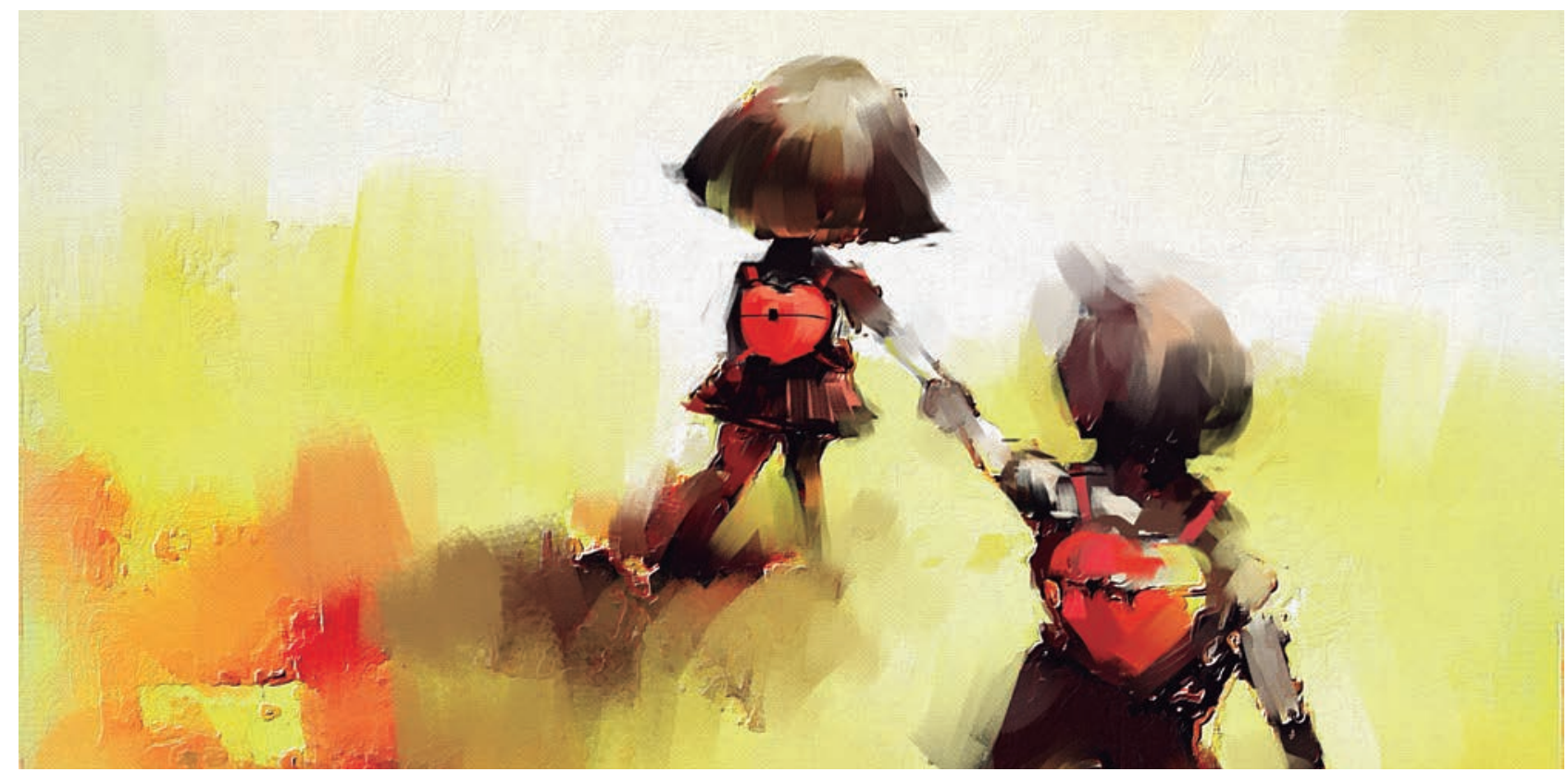

\section{Los sonidos de mi colegio}

Los diferentes sonidos que inundan mi colegio marcan las horas escolares, las diferentes actividades, los acontecimientos especiales, las celebraciones... Y por supuesto diferencian los días de comienzo de curso, los días cercanos a los periodos de vacaciones, y el final de curso.

En septiembre se cuida muy especialmente la incorporación de los más pequeños, algunos no han cumplido los tres años. Se escuchan algunos Ilantos que son consolados por sus tutores y por sus hermanos y hermanas para acabar en risas y juegos.

Según avanza el curso se ove con más claridad el bullicio al subir las escaleras a la entrada, a la salida y por supuesto durante el recreo. Al terminar las clases de la mañana se organiza un alegre alboroto para acudir al comedor y a continuación a los juegos de patio.

Mientras preparo mis clases me encanta oír, desde la ventana de mi clase, el sonsonete de los chiquillos jugando a los gogos, las cartas, el balón, la comba, el pillapilla, las construcciones y tantos juegos que inventan.

Al acercarse la fiesta de Navidad, preparan el recital de villancicos, todo se inunda de cantos; próximo el Día de la Paz, recitan poesías; Ilega el Carnaval, la algarabía es sensacional; en abril tenemos la semana cultural con el certamen literario, los calurosos aplausos se oyen desde todo el centro; ya Ilega San Isidro, los pequeños bailan el chotis; fiesta de despedida y las graduaciones en compañía de todas las familias, anuncian el final del curso.

iSonidos entrañables que tanto echo de menos en estos días de estar en casa por culpa del virus! No dejo de pensar en cómo lo estarán pasando los escolares y sus familias.

Me alegró conocer que la normativa permitía pasear a los alumnos y alumnas con trastorno del espectro autista, en nuestro centro contamos con un aula Colorines que los prepara para la inclusión en la sociedad.

También están escolarizados niños y niñas con necesidades educativas especiales atendidos por sus tutoras y tutores junto con
Encarnación Oliver Rueda CEIP Arquitecto Gaudí (Madrid)

el equipo de apoyo en el que estoy incluida. Este equipo lo formamos las profesoras especialistas en Pedagogía Terapéutica y la profesora de Audición y Lenguaje.

Los colegios cerrados, solitarios, silenciosos, ¿qué puedo hacer? No lograba parar en mi casa pensando en cómo ayudarles, cómo llegar a ellos. Desde la Conserjería de Educación de la Comunidad de Madrid nos ofrecieron cursos de formación en TIC y a los pocos minutos estaba matriculada para aprender a crear un blog. Me ha supuesto muchas horas y quebraderos de cabeza, pero ya lo tengo, el diario de trabajo crece y son muchas las actividades de lengua y matemáticas para los niños y las niñas.

Está claro que ninguna herramienta informática podrá sustituir a las clases presenciales. La relación entre profesoras, profesores y escolares, así como la interacción entre iguales, es fundamental para el desarrollo armónico y equilibrado de las personas.

La risa y la alegría de nuestros niños y niñas no nos puede faltar. Volveremos a encontrarnos, lo celebraremos con cantos, bailes, poesías y muchos juegos.

Nuestra querida y fantástica escritora Gloria Fuertes nos lo recita claramente en esta poesía:

Todo está en su sitio Los lobos en el monte Los pollitos en el corral Los peces en el agua Los barcos en el mar.

Ya todo está en su sitio, Ya todo en su lugar. Los niños en la escuela y los patos a volar.

GLORIA FUERTES• 